\title{
Erratum to: Description, analysis, and classification of biomedical signals: a computational intelligence approach
}

\author{
Adam Gacek · Witold Pedrycz
}

Published online: 21 July 2015

(C) Springer-Verlag Berlin Heidelberg 2015

Erratum to: Soft Comput (2013) 17:1659-1671

DOI 10.1007/s00500-012-0967-5

Unfortunately, the author had overlooked to provide the granting agency details in the acknowledgement section of the original publication. The correct acknowledgment section should read as:

Acknowledgments This research was supported by the Polish National Science Centre, Decision No. DEC-2011/03/B/ST7/01875.

The online version of the original article can be found under doi:10.1007/s00500-012-0967-5.

\footnotetext{
A. Gacek ( $\square)$

Institute of Medical Technology and Equipment (ITAM),

118 Roosevelt Street, Zabrze 41-800, Poland

e-mail: adam.gacek@itam.zabrze.pl

W. Pedrycz

Department of Electrical and Computer Engineering,

University of Alberta, Edmonton, AB T6R 2V4, Canada

W. Pedrycz

Department of Electrical and Computer Engineering, Faculty of Engineering, King Abdulaziz University,

Jeddah 21589, Saudi Arabia
} 